\title{
THE INFLUENCE OF DRILL POINT GEOMETRY ON TOOL LIFE
}

\author{
Zlatko BOTAK, Katarina PISAČIĆ, Marko HORVAT, Damir MAĐERIĆ
}

\begin{abstract}
Drilling is a cutting process that uses a rotary cutting tool to cut a cylindrical hole in a solid material. During machining, drill bits are exposed to rapid wear at high temperature. Sometimes, due to an ecological need for dry technology without any lubricant, the use of drill bits with coatings is required, typically titanium nitride (TiN), titanium carbon nitride (TiCN) or titanium aluminium nitride (TiAIN). This paper presents research on drilling done to determine how drill point geometry affects the drill lifetime and finished surface quality. We compared the chip removal ability and surface quality of bored holes in Hardox 500 created with high-speed steel drill bits and drill bits manufactured from hard metals, with and without coatings, under constant processing parameters. A cost/efficiency comparison was also carried out with respect to drill bit fabrication, sharpening, and use. Based on the data obtained on the damage drill points, the most economical drill bit for processing holes was determined.
\end{abstract}

Keywords: drill bits; drill point geometry; drilling

\section{INTRODUCTION}

Drilling is a machining process used to create satisfactory surface quality cylindrical holes at low cost. A drill bit used to create a hole has a cylindrical shape with cutting edges that taper to a sharp drill point. The spindle of the drill press clamps to the shank of the drill bit via the chuck, allowing transfer of rotation and cutting force/pressure to the drill bit to create a hole via the drill point. During the drilling process, as the interconnections of material particles are destroyed during cutting, the drill bit is exposed to mechanical, thermal, and chemical influences, or wear.

The durability and lifetime of the drill bit depends on the drill bit material, the workpiece material, operating modes, and, most importantly, the cutting speed. Commonly, a lubricant is used during drilling to dissipate the heat generated during the cutting process.

Due to economic and ecological reasons, drilling is sometimes carried out without a lubricant. In this case, the drill bit used is coated with a layer resistant to wear and high temperatures. Low-cost coating materials include titanium nitride (TiN) and titanium aluminium nitride (TiAlN).

Initial research has focused on identifying the optimal cutting speed and feed for different materials to increase the lifetime of the drill bit tool, i.e. the time between two sharpenings.

In this study, the effects of drill bit coating and geometry of the drill point on the drill bit lifetime were examined. The chip removal ability and surface quality of holes bored into the material Hardox 500 from drilling with high-speed steel (HSS) and hard metal drill bits were compared. The drill bits were sharpened with different drill point geometries and had different coatings. BU7 (5\%) was used as the lubricant.

\section{LITERATURE REVIEW}

In [1], the authors predicted the tool life for coated and uncoated twist drill bits. They conducted experiments to establish empirical drill-life cutting speed equations for three coatings. Drilling was performed as the cutting speed and feed rate were varied. The results revealed that none of the three coatings offered any statistically significant advantage over the others in terms of the drill life.

In [2], an experimental analysis compared the performances of coated and uncoated twist drill bits to determine the effects of various input machining parameters: cutting speed, feed rate, point angle, and drill diameter, on machine milling under dry conditions. Analysis of variance results confirmed the validity of the established mathematical models describing the effect of finish drilling processing parameters on chip load, torque, and machining time.

A comparison of the abilities of coated and uncoated carbide drill bits to drill a Ti workpiece was presented in [3]. Experimental results were discussed based on machine tool vibration, thrust force, torque, burr dimensions, and surface roughness.

In [4], tool wear, surface roughness, and power requirements were presented for drilling operation using coated and uncoated HSS tools. The authors compared the characteristics of HSS drill bits coated with TiN and TiAlN for machining under dry conditions.

In [5], the authors investigated the effects of drill point geometry and drilling technique by drilling a Ti alloy. They used uncoated carbide drills with different geometries, under various cutting speeds and drilling methods. The experimental results revealed that both drill geometry and drilling techniques affect tool wear and tool life performance when drilling titanium alloy.

In [6], the authors explored the influence of drill bit geometry on the lifetime of a tool. Several types of drill bits, with and without coatings, were used to drill holes in steel. Microscopy analysis was used to evaluate the damage to the cutting tool blade. 


\section{MATERIALS AND DRILL POINTS OF DRILL BITS}

Hard metal mark P01 (ISO 4499), obtained by sintering, is commonly used to make the drill bits. It consists of metal carbides for carrier hardness, including tungsten carbide (WC), titanium carbide (TiC), tantalum carbide $(\mathrm{TaC})$, and niobium carbide $(\mathrm{NbC})$, with cobalt (Co), nickel (Ni), and/or molybdenum (Mo) as binders.

Metal carbides have a hardness of 1300 to $1800 \mathrm{HV}$; at $1,000{ }^{\circ} \mathrm{C}$, these values are reduced by $\sim 10 \%$. At $700{ }^{\circ} \mathrm{C}$, sintered hard metals with TiC are harder than HSS at room temperature [6]. They have a high melting point, abrasion and wear resistance, high modulus of elasticity, high temperature stability, resistance to temperature changes, corrosion resistance, and high thermal and electrical conductivity.

The particle size of WC, in particular, is one parameter that directly affects the main properties of hard metals: hardness and toughness. Composition (e.g. \%Co), pressing forces, temperature, and sintering time also have some effect, but to a lesser degree.

The flute length of the drill bits, i.e. the length of the spiral groove cutting edges, and the overall tool length, depend on the standard to which they are made. In standard designs, the flute length of the drill is commonly $3 \cdot d, 4 \cdot d$, $5 \cdot d, 8 \cdot d$, or $12 \cdot d$, where $d$ is the diameter of the drill bit. For specific designs, a common flute length is the drilling depth $+4 \mathrm{~mm}[6]$.

The working body of the twist drill has a conical working tip and two spiral grooves (flute) for pulling out scrapings and delivering cooling liquids/lubricants. The drill bit body is tapered from the tip/point to the shank in a ratio of $1: 1,000$ or $0.1 \mathrm{~mm}$ to each $100 \mathrm{~mm}$ of flute length (Fig. 1). This reduces the friction between the non-cutting part of the tool and the workpiece material and prevents the tool from becoming wedged in the material.

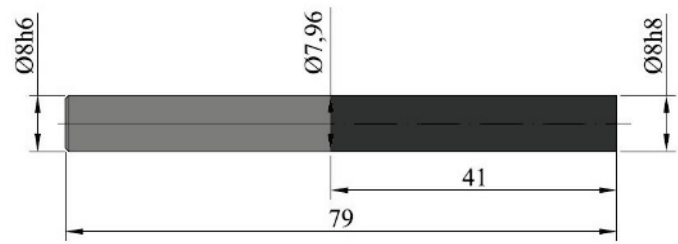

Figure 1 Removing the cone of the body

With regard to the cross-section of the drill bit at the drill point end, the web thickness of the drill bit increases toward the shank, as well as the chisel edge length, to increase tool strength. The shank, the solid cylindrical portion of the drill bit held by the chuck, is made according to DIN 6537 (tolerance h8) and DIN 6535 HA (tolerance h6). The shank length for an $\varnothing 8$-mm diameter drill is 41 $\mathrm{mm}$, the total length is $79 \mathrm{~mm}$, and the maximum drilling depth is $36 \mathrm{~mm} \mathrm{[6].}$

In our study, the workpiece material for the drill bits was already ground to tolerance $\mathrm{H} 6$, so it was not necessary to process the shank. Only the cone $(1: 1,000)$ of the body was removed, which was $0.041 \mathrm{~mm}$ of the $41-\mathrm{mm}$ length
(Fig. 1). After grinding the cone of the drill bit body on a circular grinder, final grinding of the drill point was carried out with a computer numerical control tool grinder. Diamond cutters were used to construct the flutes and drill points.

The appropriate geometry of the cutting end of the drill bit depends on the workpiece material being processed. Thus, the drill points can take several different shapes, depending on the application. In our study, a standard-point drill bit, a split-point drill bit, a four-facet drill point, and a split point with a double margin were used.

The standard-point drill bit (Fig. 2) is mainly used in small-diameter drills for drilling soft steels, such as aluminium and its alloys, wood, and plastics. It is not resistant to wear.

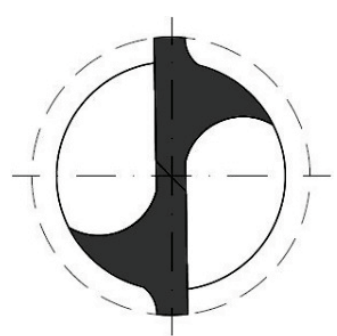

Figure 2 Standard-point drill bit

With a split-point drill bit (Fig. 3), metal is removed from the conventional drill point, and the web thickness at the chisel edge is reduced, such that less feed pressure is required for penetration into the material. The drill web has a small radius and is suitable for processing carbon steel, cast iron, and alloyed steels, up to 1,000 MPa.

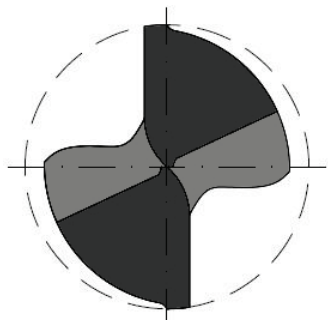

Figure 3 Split-point drill bit

A drill bit cone of $0.2 / 100 \mathrm{~mm}$ yields high-quality holeprocessing. The cutting speed $v_{\mathrm{c}}$ is $60-100 \mathrm{~m} / \mathrm{min}$ without cooling and $70-120 \mathrm{~m} / \mathrm{min}$ with cooling, given a feed, $f$, of $\sim 0.025 \cdot d \mathrm{~mm} / \mathrm{rev}$. In fabricating the split-point drill bit, splitting and thinning of the drill point must be performed accurately with the grinding machine to ensure symmetry. A lack of symmetry in the length of the cutting lips leads to one cutting edge doing more work than the other; thus, without symmetry, the cutting forces would be unbalanced, the finished hole would not be round, and the tool wear would occur more rapidly.

Above 1,000 MPa, a four-facet drill bit (Fig. 4) is used to process stainless steel, cast iron, alloy steels, titanium alloys, and Ni alloys. The chisel edge comes with a selfcentring point that eliminates the need for centre punching and pilot holes. The drill point of a four-facet drill bit 
includes a separate cutting lip and secondary clearance facets. The primary facet angles depend on the processing material, while the secondary facet angles are commonly $20^{\circ}$.

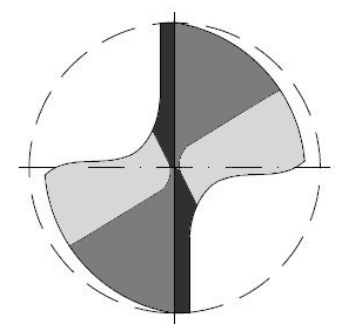

Figure 4 Four-facet drill point

The typical cutting speed with the four-facet drill ranges from $20-50 \mathrm{~m} / \mathrm{min}$ without cooling and from $25-60 \mathrm{~m} / \mathrm{min}$ with cooling, given a feed $f$ of $\sim(0.0080-0.02) \cdot d, \mathrm{~mm} / \mathrm{rev}$, depending on the strength of the material being processed.

A split point with double margin drill bit (Fig. 5) is used in the processing of carbon steel, grey cast iron, cast iron, and alloyed steels up to $1,000 \mathrm{MPa}$ and higher, depending on the desired quality of the machined surface (flatness tolerance).

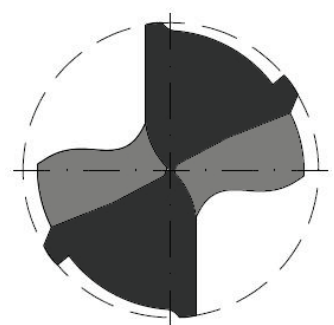

Figure 5 Split point with double margin

This drill bit is designed for drilling close-tolerance holes. Good conditions correspond to a machined surface quality of N8; very good conditions can be achieved at N7. It is manufactured with two margins, one at each end. The cutting speed is in the range of $60-100 \mathrm{~m} / \mathrm{min}$ without cooling and $70-120 \mathrm{~m} / \mathrm{min}$ with cooling, given a feed of $0.025 \cdot d, \mathrm{~mm} / \mathrm{rev}$.

\section{EXPERIMENTAL RESULTS}

In this study, two drill bits of HSS material with standard drill point geometry, and four drill bits manufactured from hard metal with three drill point geometries (split, four-facet, and double margin), were compared (Tab. 1).

The objective was to determine and compare the chip removal ability and surface quality of the bored holes created by the drilling bits when drilling holes in Hardox 500 material. Tab. 2 lists the mechanical properties of Hardox 500.

A cost/efficiency comparison for drill bit fabrication, sharpening, and use is also provided.
Table 1 Drill bits

\begin{tabular}{|c|c|c|}
\hline Drill bit & Drill point geometry & Coating \\
\hline 1 (HSS) & Standard & - \\
\hline 2 (HSS $8 \%$ Co) & Standard & - \\
\hline 3 & Split & - \\
\hline 4 & Four-facet & TiN \\
\hline 5 & Four-facet & TiAlN \\
\hline 6 & With double margin & - \\
\hline
\end{tabular}

Table 2 Mechanical properties of Hardox 500 material

\begin{tabular}{|l|c|}
\hline \multicolumn{1}{|c|}{ Properties } & Value \\
\hline Tensile strength (MPa) & 1580 \\
\hline Yield strength $(\mathrm{MPa})$ & 1250 \\
\hline Elongation (\%) & 10 \\
\hline Density $(\mathrm{g} / \mathrm{cm} 3)$ & 7850 \\
\hline Hardness $(\mathrm{HB})$ & 500 \\
\hline
\end{tabular}

Drilling was performed on a classic milling machine at a speed of $355 \mathrm{rev} / \mathrm{min}$. The cutting speed was $8.92 \mathrm{~m} / \mathrm{min}$ for a drill bit diameter of $8 \mathrm{~mm}$, and the point angle of the drill bits was $118^{\circ}$.

The costs of HSS drillings, fabrication time (metal + coating), and sharpening time are listed in Tab. 3 .

Table 3 Price of drill bits

\begin{tabular}{|c|c|c|c|}
\hline Drill bit & Price, $€$ & $\begin{array}{c}\text { Fabrication time, } \\
\text { min }\end{array}$ & $\begin{array}{c}\text { Sharpening time, } \\
\text { min }\end{array}$ \\
\hline 1 (HSS) & 1.1 & - & 1.85 \\
\hline 2 (HSS $8 \%$ Co) & 3.2 & - & 1.85 \\
\hline 3 & 14.8 & 7.1 & 2.59 \\
\hline 4 & 17.9 & 7.5 & 3.35 \\
\hline 5 & 18.0 & 7.5 & 3.35 \\
\hline 6 & 14.8 & 9.2 & 3.35 \\
\hline
\end{tabular}

Each drill bit was used to drill holes in Hardox 500 (thickness: $25 \mathrm{~mm}$ ), until the drill point became dull or the drill bit broke. The drilling results are shown in Fig. 6.

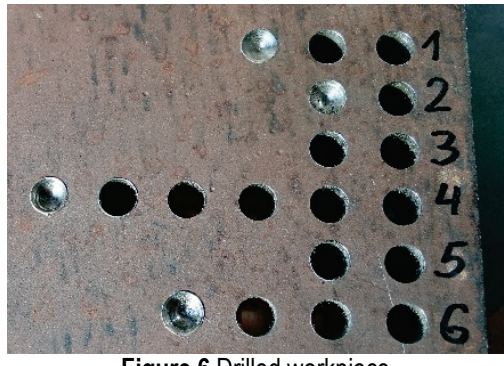

Figure 6 Drilled workpiece

Table 4 Cost per $\mathrm{mm}$ bore length

\begin{tabular}{|c|c|c|c|}
\hline Drill bit & $L, \mathrm{~mm}$ & Price, $€$ & $€ / \mathrm{mm}$ \\
\hline 1 (HSS) & 51 & 1.5 & 0.029 \\
\hline 2 (HSS $8 \%$ Co) & 27 & 3.2 & 0.119 \\
\hline 3 & 43 & 14.8 & 0.344 \\
\hline 4 & 127 & 17.9 & 0.141 \\
\hline 5 & 34 & 18.0 & 0.529 \\
\hline 6 & 77 & 14.8 & 0.192 \\
\hline
\end{tabular}

Finally, for each drill bit, the total drilling length and drilling cost per millimetre of drilled hole were calculated; the results are given in Tab. 4. We assumed that when making the tool, the price per hour was $50 €$. 


\section{CONCLUSION}

Due to the high yield strength of the workpiece material, the drilling was performed with cooling, including that done with the two coated drill bits. Because the coatings serve as an insulator and send the heat generated into the chips, the two drill bits with coatings would have an advantage over the others.

All of the drill bits had a point angle of 118 degrees, which is an acceptable angle for use in most materials, although it does not perform as well as the optimum angle for machining Hardox 500 material. It is known that harder workpiece materials require a larger point angle, and softer materials a sharper angle, to control wandering, chatter, hole shape and wear rate.

The chip removal process of all drill bits tested (1-6) was good, until the drill point became dull or the drill bit broke. In drill bit no. 3 a fracture occurred and all the others experienced dulling of, or damage to, the cutting edge, after which the drill bit could no longer drill into the material.

Although it would be expected that drill bits of hard metal offer significantly improved durability, this was not the case in our test results. Under identical operating conditions, the drill bit with the TiN coating performed the best; the other drill bits fabricated from hard metal did not meet expectations.

Drill point geometry did not have a noticeable effect on the lifetime of the drill bit, although the surfaces of the bores drilled with the hard metal drill bits were of better quality. The results also revealed that the HSS drill bit with the standard drill bit geometry was the most cost-effective way to produce bores in the material; re-sharpening of the drill bits from hard metal was not profitable in this case.

It was assumed that re-sharpening was done correctly; this means that the point angle, lip relief angle and length of the cutting edges must be exactly as established and did not occur material structural modifications.

\section{REFERENCES}

[1] Jaromír, A. (2015). A Study of the Effect of Coatings on the Drill Life. International Journal of Mechanical Engineering Research and Technology, 1(1), 46-59.

[2] Kadam, M. S. \& Pathak, S. S. (2011). Experimental Analysis and Comparative Performance of Coated and Uncoated Twist Drill Bit Dry Machining. International Journal of Mechanical Engineering Research and Technology, 1(1), 33-37.

[3] Suresh, B. K., Vijayan, V., \& Baskar, N. (2016). Comparison of coated and uncoated carbide drill bits for drilling titanium grade 2 material. Mechanika, 22(6), 571-575.

[4] Karthik, V. \& Puneeth, H. V. (2016). Tool Wear, Surface Roughness, and Power Requirement for Drilling Operation Using Uncoated and Coated HSS Tool. Imperial Journal of Interdisciplinary Research, 2(8), 1277-1287.

[5] Wong, F. R., Sharif, S., Kamdani, K., \& Rahim, E. A. (2008). The Effect of Drill Point Geometry and Drilling Technique on Tool Life when Drilling Titanium Alloy, Ti-6Al-4V. Proc. International Conference on Mechanical \& Manufacturing Engineering, Johor Bahru, Malaysia, May 2008, 1-8.

[6] Trupković, I., \& Botak, Z. (2014). Utjecaj geometrije rezne oštrice na vijek trajanja svrdla. Tehnički glasnik, 8(1), 59-63.
[7] https://www.google.hr/url?sa=t\&rct=j\&q=\&esrc $=$ s\&source=web\&cd=7\&ved=0ahUKEwjSovW34 zWAhXIW hQKHbjDC2EQFgg6MAY\&url=http\%3A\%2F\%2Fnemes.or g\%2F2005\%2520May\%2520Meeting\%2Fdrills.pdf\&usg=AO vVaw1tlhP5g2TGryCJMjVqmlaD (Accessed: 17.10.2017)

[8] https://www.google.hr/url?sa=t\&rct $=\mathrm{j} \& \mathrm{q}=\&$ esrc $=$ s\&source=web\&cd $=1 \&$ ved $=0$ ahUKEwjZ2cPj0obXAhVKKs AKHbAsC7MQFggkMAA\&url=http $\% 3 \mathrm{~A} \% 2 \mathrm{~F} \% 2 \mathrm{Fwww}$.saar stahl.com\%2Fsag\%2Fdownloads\%2Fdownload\%2F12970\&u sg=AOvVaw3y8WXgAcIpbL1ExwgsHEFy (Accessed: 17.10.2017)

Authors' contacts:

Zlatko BOTAK, PhD

University North

Department of Mechanical Engineering

104. brigade 1, HR-42000 Varaždin, Croatia

042493 339, zlatko.botak@unin.hr

Katarina PISAČı́́, Lecturer

University North

Department of Mechanical Engineering

104. brigade 1, HR-42000 Varaždin, Croatia

042493 327, katarina.pisacic@unin.hr

Marko HORVAT, Lecturer

University North

Department of Mechanical Engineering

104. brigade 1, HR-42000 Varaždin, Croatia

042493 366, marko.horvat@unin.hr

Damir MAĐERIĆ, Senior Lecturer

University North

Department of Mechanical Engineering

104. brigade 1, HR-42000 Varaždin, Croatia

042493 324, damir.madjeric@unin.hr 